\title{
Influence of preservation methods on the bioactivity of mangaba (Hancornia speciosa Gomes) from the Brazilian savannah
}

\author{
Ladyslene Christhyns PAULA ${ }^{1}$, Flávio Alves SILVA², Edson Pablo SILVA ${ }^{2 *}$, Eduardo Ramirez ASQUIERI ${ }^{2}$, \\ Clarissa DAMIANI ${ }^{2}$
}

\begin{abstract}
This study aimed to evaluate the behavior of the bioactive compounds and the antioxidant activity of raw mangaba fruit (Hancornia speciosa Gomes), in addition to the influence of preservation methods (freezing, lyophilization, and foam layer drying) on these biocompounds. Samples were evaluated for ascorbic acid, phenolic compound, and carotenoid content and total antioxidant activity by the DPPH, ABTS, and FRAP methods. The analyses were performed in triplicate for each sample and the results were expressed as the mean \pm standard deviation. A significant correlation was observed between the content of total phenolic compounds and the total antioxidant activity, as determined by the FRAP method, which showed that the content of ascorbic acid contributed to the antioxidant activity of the samples. The lyophilization process produced the best results for ascorbic acid (372.80 mg/100 g), phenolic compounds (408.86 mg AGE/100 g), and carotenoids (0.19 mg/100 g). Therefore, as mangaba may be consumed as both a fresh fruit and in a processed form, new markets can be conquered, enabling the fruit to be used as functional food.
\end{abstract}

Keywords: native fruit trees; Apocynaceae; chemical characterization; preservation.

Practical Application: The knowledge of new raw materials rich in bioactive compounds with a high nutritional content, and the study of new methods of conservation are essential for the development of new food products to contribute to the preservation and propagation of Brazilian fruits.

\section{Introduction}

Brazil is known for the wide biological diversity of its flora and is considered to be one of the main centers of genetic diversity of fruit species in the world. Researchers have associated the consumption of fruit with beneficial effects on human health, such as the decreased incidence of chronic degenerative diseases and even cancer (Leong \& Shui, 2002; Vasco et al., 2008). These beneficial effects result from the protective effects of physiologically active substances such as minerals, carotenoids, vitamins, and phenolic compounds, which interfere with specific targets and modulate the antioxidant defenses against the inflammatory and mutagenic processes that occur in several diseases (Rufino et al., 2010).

Mangaba stands out among the native fruits of the Brazilian savanna owing to its high nutritional value of $1.20 \%$ protein, $2.37 \%$ lipid, $10.0 \%$ carbohydrate, and $3.40 \%$ fiber. It also contains vitamins $\mathrm{A}, \mathrm{B} 1, \mathrm{~B} 2$, and $\mathrm{C}$, and minerals such as phosphorus, calcium, and iron. The association of iron with vitamin $\mathrm{C}$ is an important characteristic of its composition because this vitamin increases the bioavailability of iron in the body. Some studies also show that mangaba can efficiently treat and prevent gastric ulcers, even stomach cancer, because it stimulates mucus synthesis and produces an anti-secretory effect, as well (Moraes et al., 2008).
In addition to its nutritional benefits, the fruit of the mangaba tree is sensorially attractive, such as its peculiar and intense color, taste, and smell (Souza et al., 2012). The importance of the mangaba fruit arises from not only its nutritional and medicinal value, but also plays a fundamental role in the socioeconomic and environmental value, as it contributes to income generation and conservation of the Cerrado biome.

Considering the potential of native species and the need to propose preservation technologies such that the value of mangaba fruit can be increased and the Brazilian savanna biome could be preserved, this study aimed to evaluate the behavior of bioactive compounds and the antioxidant activity of raw mangaba fruit (Hancornia speciosa Gomes) preserved by different methods.

\section{Materials and methods}

\subsection{Fruit harvesting and sample preparation}

Ripe mangaba fruits were harvested in 2014 in the Agronomy School, located in Goiânia, GO, Brazil ( $16^{\circ} 35^{\prime} 12^{\prime \prime} \mathrm{S}, 49^{\circ} 21^{\prime} 14^{\prime \prime} \mathrm{W}$; altitude: $730 \mathrm{~m}$ ).

Immediately after harvest, the fruits were pulped by a mechanical fruit pulping machine and divided into three batches. The first

${ }^{1}$ Departamento de Engenharia de Alimentos, Fundação Universidade Federal de Rondônia - UNIR, Campus Ariquemes, Ariquemes, RO, Brasil

${ }^{2}$ Setor de Engenharia de Alimentos, Escola de Agronomia, Universidade Federal de Goiás - UFG, Campus Samambaia, Goiânia, GO, Brasil

*Corresponding author: edsonpablos@hotmail.com 
was frozen, the second was subjected to lyophilization in up to $6 \%$ humidity (by using infra-red equipment) and the third was dried in foam layers in up to $6 \%$ humidity ( $5 \%$ emulsifier based on propylene glycol, fatty acid monoglycerides and potassium stearate, $2 \%$ guar gum, and sucrose-based thickener).

\section{In vitro antioxidant activity}

\section{Extract preparation}

In order to quantify the antioxidant capacity, the extracts were prepared from a methodology adapted from Rufino et al. (2010). First, $40 \mathrm{~mL}$ methanol/water $(50: 50 \mathrm{v} / \mathrm{v})$ was added to $2-10 \mathrm{~g}$ of sample, homogenized by using a mechanical shaker $\left(\right.$ CIENLAB $\left.^{\circledR}\right)$ at $25^{\circ} \mathrm{C}$, and allowed to stand for $1 \mathrm{~h}$ at room temperature $\left(24{ }^{\circ} \mathrm{C} \pm 2{ }^{\circ} \mathrm{C}\right)$. Afterwards, the solution was centrifuged at $15,000 \mathrm{rpm}$ for $15 \mathrm{~min}$ and the supernatant was transferred to a $100-\mathrm{mL}$ volumetric flask

Subsequently, $40 \mathrm{~mL}$ acetone/water $(70: 30 \mathrm{v} / \mathrm{v})$ was then added to the residue of the first filtration. This solution was shaken in the mechanical shaker again and allowed to stand for $1 \mathrm{~h}$.

Finally, the solution was centrifuged at $15,000 \mathrm{rpm}$ for $15 \mathrm{~min}$ again and the supernatant was transferred to the volumetric balloon which contained the first supernatant. The flask was filled with distilled water and the extracts were stored in amber flasks at $-18{ }^{\circ} \mathrm{C}$ until analysis.

\section{Free radical DPPH assay}

To establish the kinetic parameters of the samples, the antioxidant capacity was determined by using a slightly modified version of the 2,2-diphenyl-1-picrylhydrazyl (DPPH) method described by Brand-Williams et al. (1995). It is based on the capture of the DPPH radical by antioxidants.

After incubation in the dark for $30 \mathrm{~min}$ at room temperature, the absorbance was measured using a spectrophotometer (Gehaka 350G UV-VIS Sao Paulo, Brazil), at $515 \mathrm{~nm}$. Methyl alcohol was used as the blank solution for the calibration of the spectrophotometer. The antioxidant capacity was expressed as the concentration of antioxidant required to reduce the original quantity of free radicals by $50 \%$ (EC50). The decreased steady-state absorbance of DPPH was expressed as a value in $\mathrm{g} / \mathrm{g}$ DPPH.

\section{Radical ABTS assay}

The ABTS assay was based on a method developed by Rufino et al. (2010). ABTS•+ radical cations were produced by the reaction of $7 \mathrm{mM} \mathrm{ABTS} \mathrm{stock} \mathrm{solution} \mathrm{with} 145 \mathrm{mM}$ potassium persulfate, which was allowed to stand in the dark at room temperature for $12-16 \mathrm{~h}$ before use. The ABTS•+ solution was diluted with ethanol to produce a solution with an absorbance of $0.70 \pm 0.02$ at $734 \mathrm{~nm}$. After the addition of $30 \mu \mathrm{L}$ of sample or Trolox standard to $3 \mathrm{~mL}$ of diluted ABTS $\bullet+$ solution, the absorbance was recorded at 6 min after mixing, when the value reached a plateau. Ethanolic solutions of known Trolox concentrations were used for calibration and the results were expressed as $\mu \mathrm{M}$ Trolox/g fruit.

\section{FRAP (Ferric Reducing Antioxidant Power) assay}

The antioxidant capacity of each sample was estimated by the FRAP assay in agreement with a procedure described in the literature Brand-Williams et al. (1995). Briefly, $2.7 \mathrm{~mL}$ of freshly prepared FRAP reagent (TPTZ, $\mathrm{FeCl}_{3}$, and acetate buffer) at $37^{\circ} \mathrm{C}$ was mixed with $90 \mu \mathrm{L}$ fruit extract and $270 \mu \mathrm{L}$ distilled water. The reference blank sample contained FRAP reagent and the absorbance at $595 \mathrm{~nm}$ was determined at baseline and every $30 \mathrm{~min}$ until a plateau was reached. Aqueous solutions of known $\mathrm{Fe}$ (II) concentrations in the range of 100-1500 $\mu \mathrm{M}$ of iron sulfate $\left(\mathrm{Fe}_{2} \mathrm{SO}_{4}\right)$ were used for calibration. The results were expressed in $\mu \mathrm{mol} \mathrm{Fe}_{2} \mathrm{SO}_{4} / \mathrm{g}$.

\section{Ascorbic acid}

The determination of the content of ascorbic acid ( $\mathrm{mg}$ ascorbic $\mathrm{acid} / 100 \mathrm{~g}$ pulp) was conducted by using the spectrophotometric method of Terada et al. (1978) with dinitrophenylhydrazine (DNPH). Ascorbic acid was used the standard.

The samples were assessed by using a spectrophotometer (Gehaka 350G UV-VIS Sao Paulo City, Brazil) at $529 \mathrm{~nm}$ and the results were expressed as $\mathrm{mg}$ vitamin $\mathrm{C} / 100 \mathrm{~g}$ sample.

\section{Total phenolic compounds}

The determination of the content of total phenolic compounds used the Folin-Ciocalteau colorimetric method, with some modifications. Ether, alcoholic, and aqueous extracts were used. Extracts $(1.0 \mathrm{~mL})$ were mixed with $1 \mathrm{~mL}$ Folin-Ciocalteu reagent (1:3), $2 \mathrm{~mL} 20 \%$ sodium carbonate solution, and $2 \mathrm{~mL}$ distilled water. After $1 \mathrm{~h}$, the absorbance at $700 \mathrm{~nm}$ was measured on the spectrophotometer (Gehaka 350G UV-VIS Sao Paulo City, Brazil). The results were expressed as g gallic acid equivalents $(\mathrm{GAE}) / 100 \mathrm{~g}$.

\section{Total carotenoids}

The total carotenoids were determined by Higby's (1962) method and extracted through sample agitation with alcohol and hexane, followed by three filtrations. The readings were performed on a UV-VIS spectrophotometer (Gehaka 350G UV-VIS Sao Paulo City, Brazil) at $450 \mathrm{~nm}$ and the results were expressed as $\mathrm{mg}$ total carotenoids/100 $\mathrm{g}$ sample.

\subsection{Statistical analyses}

The analysis results of the samples were statistically evaluated by analysis of variance (ANOVA) and Tukey's test was applied at the significance level of $5 \%$. The analyses were computed by using the R Development Core Team (2012) software. All results were expressed as the mean \pm standard deviation.

\section{Results and discussion}

\subsection{Total Antioxidant Activity (TAA)}

The results of the TAA assay are shown in Table 1. All treatments were able to capture radicals DPPH and ABTS and decreased FRAP. The results of the total antioxidant activity 
Table 1. Total antioxidant capacity (DPPH, ABTS, and FRAP) in the organic-aqueous extract of mangaba pulp preserved by different methods.

\begin{tabular}{cccc}
\hline Treatments & $\begin{array}{c}\mathrm{DPPH}^{*} \\
\mathrm{EC}_{50}(\mathrm{~g} / \mathrm{g} \mathrm{DPPH})\end{array}$ & $\begin{array}{c}\mathrm{ABTS}^{*} \\
\mu \mathrm{mol} \text { Trolox} / g\end{array}$ & $\begin{array}{c}\mathrm{FRAP}^{*} \\
\mu \mathrm{mol} \mathrm{Fe}_{2} \mathrm{SO}_{4} / \mathrm{g}\end{array}$ \\
\hline Fresh & $2912.56^{\mathrm{a}} \pm 3.96$ & $18.54^{\mathrm{a}} \pm 0.68$ & $15.21^{\mathrm{a}} \pm 1.36$ \\
Frozen & $2863.29^{\mathrm{b}} \pm 2.88$ & $15.44^{\mathrm{a}} \pm 1.04$ & $12.52^{\mathrm{a}} \pm 1.26$ \\
Lyophilized & $836.03^{\mathrm{c}} \pm 2.05$ & $73.86^{\mathrm{c}} \pm 2.82$ & $206.53^{\mathrm{c}} \pm 1.78$ \\
Foam & $739.58^{\mathrm{d}} \pm 2.62$ & $54.42^{\mathrm{b}} \pm 2.20$ & $168.01^{\mathrm{b}} \pm 1.83$ \\
\hline
\end{tabular}

DPPH $=$ 2,2-diphenyl-1-picrylhydrazyl; ABTS = 2,2'-azino-bis (3-ethylbenzothiazoline6-sulphonic acid); FRAP $=$ Ferric Reducing Antioxidant Power. ${ }^{*}$ Mean \pm standard deviation of three assays. Means in the same column followed by the same letters were not statistically different $(\mathrm{p}<0.05)$, in Tukey's test.

of the treatments, measured by both methods, were attributed to the different content of bioactive compounds in every sample and to the interaction between each compound.

The antioxidant capacity measured by the ABTS method with treatments of fresh and dry material were classified, in ascending order, as: frozen $<$ fresh $>$ foam $<$ lyophilized. After accounting for the methodology of the reduction of iron ions, the antioxidant capacities of the treatments were determined to be between $12.52 \mu \mathrm{mol} \mathrm{Fe}_{2} \mathrm{SO}_{4} / \mathrm{g}$ of frozen pulp and $206.53 \mu \mathrm{mol}$ $\mathrm{Fe}_{2} \mathrm{SO}_{4} / \mathrm{g}$ of lyophilized pulp. The significant difference between the treatments for DPPH may be related to the processing of the sample, as there was a significant increase in the chemical reactions resulting from this, for example the degradation of Vitamin C.

When the results of the reducing power of the free radical DPPH in the treatments were analyzed, there was significant increase in the antioxidant capacity of the samples of lyophilized pulp and foam owing to the decrease in corresponding values of EC50, as shown in Table 1.

Studies have shown that there is an increase in the TAA of fruits and vegetables after processing (Chang et al., 2005; Ersus \& Yurdagel, 2007; Rózek et al., 2010); this may trigger important changes in their sensorial characteristics, the content of their bioactive compounds, or affect their antioxidant potential and that of any products made from those fruits and vegetables.

The increase in the antioxidant capacity may be related to food preservation methods as lyophilization and foam layer drying change the composition of the final products, because either the use of ingredients with antioxidant properties or the mere concentration of compounds increases as the result of water loss from the products. Bennett et al. (2011) studied the effect of drying conditions on total polyphenols and on the antioxidant activity of different dry fruits. The authors observed that drying conditions may affect the sensory attributes of grapes, whereas the drying conditions of prunes, currants, and apricots led to neither significant changes in total phenols nor to antioxidant activities. Peñarrieta et al. (2011) evaluated the changes in phenolic antioxidants in the lyophilization and sun-drying of potatoes by using both FRAP and ABTS methodologies. The results showed that the antioxidant activity decreased when the methodology of iron ions reduction was applied. However, it was unchanged when the ABTS method was used for analysis.
Rufino et al. (2010) compared the antioxidant capacity of 18 native fruits by the DPPH, ABTS, and FRAP methodologies and concluded that fresh mangaba ( $338.5 \mathrm{~g} / \mathrm{g} \mathrm{DPPH}, 14.6 \mu \mathrm{mol}$ Trolox/g, and $18.3 \mu \mathrm{mol} \mathrm{Fe}_{2} \mathrm{SO}_{4} / \mathrm{g}$ ) and lyophilized mangaba (89.5 g/g DPPH, $65.6 \mu \mathrm{mol}$ Trolox/g, and $163.4 \mu \mathrm{mol} \mathrm{Fe}_{2} \mathrm{SO}_{4} / \mathrm{g}$ ) had higher antioxidant activity than many fruits, including jabuticaba, jambolão, juçara, camu-camu, uvaia, and even acerola, which is known for its high antioxidant capacity.

All treatments under study preserved antioxidant capacity; however, their intensities were different. The results showed that the antioxidant capacities of the samples depended on the method used for analysis: DPPH, ABTS, or FRAP. These discrepancies of the total antioxidant capacity may be inherent to the characteristics and to the action mechanism of the bioactive compounds in addition to the methodology applied to evaluate that antioxidant property. According to Leong \& Shui (2002), vegetables, mainly fruits, are composed of several compounds with antioxidant capacity. These compounds include ascorbic acid, carotenoids, and polyphenols, whose quantity and profile vary with the type, variety, and maturation stage of the fruit and the edaphoclimatic conditions throughout cultivation.

Based on the DPPH, ABTS, and FRAP results, it was concluded that the assays performed on fresh mangaba fruits preserved by different methods showed high levels of antioxidants. Therefore, the preservation methods applied in this study (freezing, lyophilization, and foam layer drying) contributed positively to the increased levels of antioxidant compounds.

\subsection{Ascorbic acid}

Information on the content of ascorbic acid in $H$. speciosa Gomes pulp preserved by different methods is shown in Table 2 .

Significant differences in the content of vitamin $C$ after each treatment was observed; there was great variation in the content of ascorbic acid, from low levels in the pulp subjected to foam layer drying $(78.29 \mathrm{mg} / 100 \mathrm{~g})$ to high levels in the lyophilized pulp $(342.80 \mathrm{mg} / 100 \mathrm{~g})$. The differences between treatments, especially for foam, may be related to the incorporation of oxygen during the process used to obtain the product, together with the drying temperature used to obtain the final product. These contents may be considered significant compared with other tropical fruits such as açaí, cashew, and cajá.

The content of vitamin $C$ is a feature of mangaba. Researchers have reported great variety in the concentration of vitamin C. Moura et al. (2002) reported vitamin C content of $139.64 \mathrm{mg} / 100 \mathrm{~g}$ in fruits of mangaba trees in Rio Grande do Norte state.

The decrease in the content of vitamin $\mathrm{C}$ after foam layer drying may have been a result of ascorbic acid oxidation; this reaction is accelerated in the dehydration process in foam layer heating and aeration, but delayed in lyophilization because the pulp remains frozen and under vacuum throughout the whole process (Liaotrakoon et al., 2013).

Under the conditions used for processing, it is known that ascorbic acid is rapidly oxidized owing to exposure to air, heat, light, and alkaline pH (Nelson et al., 2006). Losses may 
Table 2. Content of ascorbic acid of mangaba pulp preserved by different methods .

\begin{tabular}{cc}
\hline Treatments & $\begin{array}{c}\text { Ascorbic Acid } \\
(\mathrm{mg} / 100 \mathrm{~g})\end{array}$ \\
\hline Fresh & $193.07^{\mathrm{b}} \pm 1.53$ \\
Frozen & $159.48^{\mathrm{c}} \pm 1.57$ \\
Lyophilized & $342.80^{\mathrm{a}} \pm 3.62$ \\
Foam & $78.29^{\mathrm{d}} \pm 0.90$ \\
\hline
\end{tabular}

${ }^{*}$ Mean \pm standard deviation of three assays. Means in the same column followed by the same letters had no statistical difference $(\mathrm{p}<0.05)$, in the Tukey's test.
Table 3. Total phenolic compounds of mangaba subjected to ethanolic, aqueous, and ether extraction.

\begin{tabular}{lccc}
\hline \multirow{4}{*}{ Sample } & \multicolumn{3}{c}{ Total Phenolic Compounds (mg AGE/100 g) } \\
\cline { 2 - 4 } & \multicolumn{1}{c}{ Ethanolic $^{\star}$} & Aqueous $^{\star}$ & Ether $^{\star}$ \\
\hline Fresh & $60.40^{\mathrm{a}} \pm 2.80$ & N.R. & N.R. \\
Frozen & $66.50^{\mathrm{a}} \pm 0.99$ & N.R. & N.R. \\
Lyophilized & $408.86^{\mathrm{bA}} \pm 1.86$ & $289.57^{\mathrm{aB}} \pm 2.83$ & N.R. \\
Foam & $237.33^{\mathrm{CA}} \pm 1.91$ & $275.12^{\mathrm{aA}} \pm 0.89$ & N.R. \\
\hline${ }^{*}$ Mean
\end{tabular}

${ }^{*}$ Mean \pm standard deviation of three assays. N.R. $=$ no reading.

the lyophilization process leads to a decrease in the volumes of the samples and the concentration of their constituent compounds.

The comparison of the different types of extractions under investigation revealed significant differences between the lyophilized samples, with the ethanolic extraction leading to a higher content (408.86 mg AGE/100 g) than the aqueous extraction (289.57 $\mathrm{mg}$ AGE/100 g). For the sample subjected to foam layer drying, no significant difference was observed between the ethanolic extract (237.33 mg AGE/100 g) and the aqueous extract (275.12 mg AGE/100 g). Water, considered the universal solvent, was not very efficient as an extraction solvent. Combined with other organic solvents, it contributes to create a moderately polar mean, an environment that favors the extraction of polyphenols (Lapornik et al., 2005; Liyana-Pathirana \& Shahidi, 2005).

The presence of significant differences in the phenolic contents of the extracts indicates that the solvent affected the profiles of the phytochemicals found in the sample. As phenolic compounds have different polymerization levels, their extraction is dependent on their solubility in pure or diluted organic solvents (Leong \& Shui, 2002). The solubility in particular solvents is a characteristic of each phytochemical. The lack of a universal extraction procedure is justified, not only because phenolic compounds have different structures and sensitivity, but also because extraction conditions may vary.

Rufino et. al., (2010) studied the content of total polyphenols extracted from 18 fruit species with methanol/acetone/water and obtained $169.4 \mathrm{mg} / 100 \mathrm{~g}$ in fresh mangaba and $934.9 \mathrm{mg} / 100 \mathrm{~g}$ in lyophilized mangaba. These values were higher than those found in this study. Observed a wide variation among mangaba genotypes of between 161.45 and $366.83 \mathrm{mg}$ gallic acid/100 g; the mean value was $220.06 \mathrm{mg}$ gallic acid/100 g.

Siqueira et al. (2013) reported $113 \mathrm{mg} / 100 \mathrm{~g}$ total phenolic compounds in the ethanolic extract of mangaba. This was higher than the content found in this study.

After accounting for the drying processes used in this study, lyophilization enabled products with higher amounts of bioactive compounds to be obtained in comparison with foam layer drying. Although the process is shorter than lyophilization, foam layer drying was applied at higher temperatures whereas drying in a freeze-dryer takes many hours as the apparatus operates at lower temperatures, thereby avoiding the loss of compounds which are sensitive to light and oxygen, for instance. 
Peng et al. (2013) yielded flowers made of purple sweet potato by drying them with different carriers and observed the protective effect of these carriers on the contents of anthocyanins, flavonoids, and total phenolic compounds, by comparison with samples without carriers. Maltodextrin was the carrier that exerted the greatest protective effect on these compounds. The protective effect of maltodextrin and other carriers (gums and starch) was also observed by Idham et al. (2012).

Although carriers used by this study are not the same used by previously mentioned authors, it may be stated that, despite the association of foam layer and drying high temperature, there was no loss of phenolic compounds. This was associated with the use of a carrier made of guar gum. As shown by other studies, this agent may have exerted physical protection on smaller molecules (e. g., phenolic compounds) because it is constituted by macromolecules. Samples with smaller contents, or the ones which do not use carriers, tend to be more hygroscopic; thus, they absorb more water and make degradation reactions easier (Tonon et al., 2010).

The results showed the importance of the selection of an adequate solvent to extract phenolic compounds for vegetable extracts and of using carriers. Taking into account the solvents under investigation, ethanol was the most effective extraction agent to recover phenolic compounds in mangaba, with the lyophilization process shown to be the most efficient method to maintain the phenolic compound content, probably due to the use of lower temperature and pressure than other preservation methods.

\subsection{Carotenoids}

Carotenoids are important precursors of vitamin C and have a considerable level of antioxidant activity. Treatments under analysis in this study provided between $0.05 \mathrm{mg} / 100 \mathrm{~g}$ and $0.27 \mathrm{mg} / 100 \mathrm{~g}$ carotenoids, as shown in Table 4 .

The highest means were found in the fresh sample $(0.27 \mathrm{mg} / 100 \mathrm{~g})$, followed by the lyophilized sample $(0.19 \mathrm{mg} / 100 \mathrm{~g})$ and the foam-dried sample $(0.16 \mathrm{mg} / 100 \mathrm{~g})$. The values are shown in Table 4; by comparison with the ones reported by other studies of mangaba trees - described below - variation is evident, with values below, equal, and above the ones found by these studies for the contents of carotenoids.

When several native fruits are compared, there is still great variation in the contents of carotenoids. One example is Rufino et al. (2010) studied the peduncle of cashew trees in Pacajus, Ceará state, and the fruits of camu-camu in Belém, Pará state,

Table 4. Total carotenoid content of mangaba subjected to different preservation methods.

\begin{tabular}{cc}
\hline Treatment & Carotenoids $(\mathrm{mg} / 100 \mathrm{~g})^{\star}$ \\
\hline Fresh & $0.27^{\mathrm{a}} \pm 0.02$ \\
Frozen & $0.12^{\mathrm{b}} \pm 0.02$ \\
Lyophilized & $0.19^{\mathrm{ab}} \pm 0.02$ \\
Foam & $0.16^{\mathrm{ab}} \pm 0.03$ \\
\hline
\end{tabular}

${ }^{*}$ Mean \pm standard deviation of three assays. Means in the same column followed by the same letters had no statistical difference $(\mathrm{p}<0.05)$, in the Tukey's test. and found mean values of $0.4 \mathrm{mg} / 100 \mathrm{~g}$ for both fruits. These contents were higher the ones found in this study.

The concentration of carotenoids in the samples under study was higher than those found in nontraditional tropical fruits such as umbu ( $341.3 \mu \mathrm{g} / 100 \mathrm{~g})$, bacuri $(1140.7 \mu \mathrm{g} / 100 \mathrm{~g})$, murici $(1269.0 \mu \mathrm{g} / 100 \mathrm{~g})$, and uvaia $(1285.6 \mu \mathrm{g} / 100 \mathrm{~g})$.

Carotenoids have different chemical stabilities to degradation, which result in the conditions applied throughout the treatment (Gama \& Sylos, 2005). Some of the main factors that lead to carotenoid degradation, as a result of either isomerization and/or oxidation, are heat, light, enzymatic action, and oxidation triggered by peroxides that result from lipid oxidation (Rodriguez-Amaya, 2001).

In general, the content of total carotenoids decreased slightly by the preservation methods compared with the values of fresh pulp, although the difference was not statistically significant, such as the case of lyophilized pulp and the pulp dried in foam layers. The slight difference may have been influenced by the ascorbic acid content of mangaba fruit. Choi et al. (2011) stated that ascorbic acid may have a stabilizing effect on carotenoids.

The comparison of the dehydration assays under investigation shows that the concentration of the carrier used for foam layer drying did not affect carotenoid retention, as shown by the phenolic compounds (Table 3). This could be explained by the fact that the temperature used for drying resulted in smaller particles and, consequently, in an increase in the surface area. Therefore, carotenoids would be more exposed to light and oxygen throughout the process, increasing their rate of degradation. Studies have provided evidence of carotenoid degradation during the dehydration process (Southon, 1998), even in lyophilized products (Barnwal \& Tiwari, 2008).

Any chosen processing method may lead to carotenoid degradation as it depends on time, temperature, size, and disintegration of food particles.

Although the beneficial effects of carotenoids in disease prevention have been widely reported in the literature, daily requirements for the intake of carotenoids have not been established. However, the Souza et al. (2011) and Xu et al. (2007) recommend that prudent levels for the daily intake should range from 3,000 to 6,000 $\mu \mathrm{g}$ of beta-carotene, from 5,200 to $6,000 \mu \mathrm{g}$ of provitamin A carotenoids, and from 9,000 to $18,000 \mu \mathrm{g}$ of total carotenoids. Therefore, the samples under analysis may be considered rich in this feature as their consumption would provide the daily requirement of total carotenoids.

\section{Conclusion}

The evaluation of the behavior of mangaba pulp in different preservation methods demonstrated the excellent content of bioactive compounds and good antioxidant capacity. The best results were found in the lyophilized samples, which showed significant increases in ascorbic acid and other bioactive compounds. This study has provided evidence of the biological potential of mangaba, which arises from its natural bioactive compounds and high antioxidant capacity. 


\section{Acknowledgements}

The authors would like to thank the Brazilian sponsor CNPq and CAPES for financial support, and the CNPq by productivity bag.

\section{References}

Barnwal, P., \& Tiwari, G. N. (2008). Grape drying by using hybrid photovoltaic-thermal (PV/T) greenhouse dryer: an experimental study. Solar Energy, 82(12), 1131-1144. http://dx.doi.org/10.1016/j. solener.2008.05.012.

Bennett, L. E., Jegasothy, H., Konczak, I., Frank, D., Sudharmarajan, S., \& Clingeleffer, P. R. (2011). Total polyphenolics and anti-oxidant properties of selected dried fruits and relationships to drying conditions. Journal of Functional Foods, 3(2), 115-124. http://dx.doi. org/10.1016/j.jff.2011.03.005.

Brand-Williams, W., Cuvelier, M. E., \& Berset, C. (1995). Use of a free radical method to evaluate antioxidant activity. Food Science and Technology, 28, 25-30.

Chang, B., Nishikawa, M., Nishiguchi, S., \& Inoue, M. (2005). L-Carnitine inhibits hepatocarcinogenesis via protection of mitochondria. International Journal of Cancer, 113(5), 719-729. http://dx.doi. org/10.1002/ijc.20636. PMid:15499623.

Chirinos, R., Rogez, H., Campos, D., Pedreschi, R., \& Larondelle, Y. (2007). Optimization of extraction conditions of antioxidant phenolic compounds from mashua (Tropaeolum tuberosum Ruiz \& Pavon) tubers. Separation and Purification Technology, 55(2), 217-225. http://dx.doi.org/10.1016/j.seppur.2006.12.005.

Choi, J. G., Kang, O. H., Lee, Y. S., Chae, H. S., Oh, Y. C., Brice, O. O., Kim, M. S., Sohn, D. H., Kim, H. S., Park, H., Shin, D. W., Rho, J. R., \& Kwon, D. Y. (2011). In vitro and in vivo antibacterial activity of Punica granatum peel ethanol extract against Salmonella. EvidenceBased Complementary and Alternative Medicine, 2011, 690518. http:// dx.doi.org/10.1093/ecam/nep105. PMid:19687188.

Ersus, S., \& Yurdagel, U. (2007). Microencapsulation of anthocyanin pigments of black carrot (Daucuscarota L.) by spray dryer. Journal of Food Engineering, 80(3), 805-812. http://dx.doi.org/10.1016/j. jfoodeng.2006.07.009.

Gama, J. J. T., \& Sylos, C. M. (2005). Major carotenoid composition of Brazilian Valencia orange juice: identification and quantification by HPLC. Food Research International, 38(8-9), 899-903. http://dx.doi. org/10.1016/j.foodres.2005.03.008.

Haminiuk, C. W. I., Plata-Oviedo, M. S. V., Guedes, A. R., Stafussa, A. P., Bona, E., \& Carpes, S. T. (2011). Chemical, antioxidant and antibacterial study of Brazilian fruits. Journal of Food Science and Technology, 46(7), 1529-1537. http://dx.doi.org/10.1111/j.13652621.2011.02653.x.

Higby, W. K. (1962). A simplified method for determination of some aspects of the carotenoid distribution in natural and carotenefortified orange juice. Journal of Food Science, 27(1), 42-49. http:// dx.doi.org/10.1111/j.1365-2621.1962.tb00055.x.

Idham, Z., Muhamad, I. I., Mohd Setapar, S. H., \& Sarmidi, M. R. (2012). Effect of thermal processes on Roselle anthocyanins encapsulated in different polymer matrices. Journal of Food Processing and Preservation, 36(2), 176-184. http://dx.doi.org/10.1111/j.1745-4549.2011.00572.x.

Lapornik, B., Prošek, M., \& Wondra, A. G. (2005). Comparison of extract prepared from plant by-products using different solvents and extraction time. Journal of Food Engineering, 71(2), 214-222. http://dx.doi.org/10.1016/j.jfoodeng.2004.10.036.
Leong, L. P., \& Shui, G. (2002). An investigation of antioxidant capacity of fruits in Singapore markets. Food Chemistry, 76(1), 69-75. http:// dx.doi.org/10.1016/S0308-8146(01)00251-5.

Liaotrakoon, W., Clercq, N., Van Hoed, V., \& Dewettinck, K. (2013). Dragon fruit (Hylocereus spp.) seed oils: their characterization and stability under storage conditions. Journal of the American Oil Chemists' Society, 90(2), 207-215. http://dx.doi.org/10.1007/ s11746-012-2151-6.

Liyana-Pathirana, C., \& Shahidi, F. (2005). Optimization of extraction of phenolics compounds from wheat using response surface methodology. Food Chemistry, 93, 45-56.

Moraes, T. M., Rodrigues, C. M., Kushima, H., Bauab, T. M., Villegas, W., Pellizzon, C. H., Brito, A. R. M. S., \& Hiruma-Lima, C. A. (2008). Hancornia speciosa: indications of gastroprotective, healing and antihelicobacter pylori actions. Journal of Ethnopharmacology, 120(2), 161-168. http://dx.doi.org/10.1016/j.jep.2008.08.001. PMid:18761076.

Moura, C. F. H., Alves, R. E., Filgueiras, H. A. C., Araújo, N. C. C., \& Almeida, A. S. (2002). Quality of fruits native to latin america for processing: mangaba (Hancornia speciosa Gomes). Acta Horticulturae, 2(575), 549-554. http://dx.doi.org/10.17660/ActaHortic.2002.575.64.

Mukhopadhyay, S., Luthria, D. L., \& Robbins, R. J. (2006). Optimization of extractionprocess for phenolic acid from black cohosh (Cimicifuga racemosa) by pressurized liquid extraction. Journal of the Science of Food and Agriculture, 86(1), 156-162. http://dx.doi.org/10.1002/ jsfa.2326.

Naczk, M., \& Shahidi, F. (2006). Phenolics in cereals, fruits and vegetables: occurrence, extraction and analysis. Journal of Pharmaceutical and Biomedical Analysis, 41(5), 1523-1542. http://dx.doi.org/10.1016/j. jpba.2006.04.002. PMid:16753277.

Nelson, D. L., Cox, M. L. M., \& Lehninger, A. L. (2006). Princípios de bioquímica (4. ed.). São Paulo: Sarvier.

Peñarrieta, J., Salluca, T., Tejeda, L., Alvarado, J., \& Bergenstahl, B. (2011). Changes in phenolic antioxidants during chuño production (traditional Andean freeze and sun-dried potato). Journal Food Composition, 24(4-5), 580-587. http://dx.doi.org/10.1016/j.jfca.2010.10.006.

Peng, Z., Li, J., Guan, Y., \& Zhao, G. (2013). Effect of carriers on physicochemical properties, antioxidant actives and biological components of spray-dried purple sweet potato flours. LebensmittelWissenschaft + Technologie, 51(1), 348-355. http://dx.doi.org/10.1016/j. lwt.2012.09.022.

Prasad, K. N., Hassan, F. A., Yang, B., Kong, K. W., Ramanan, R. N., Azlan, A., \& Ismail, A. (2011). Response surface optimisation for the extraction of phenolic compounds and antioxidant capacities of underutilised Mangifera pajang Kosterm. peels. Food Chemistry, 128(4), 1121-1127. http://dx.doi.org/10.1016/j.foodchem.2011.03.105.

R Development Core Team. (2012). R: a language and environment for statistical computing. Vienna: R Foundation for Statistical Computing. Retrieved from http://www.Rproject.org/

Rodriguez-Amaya, D. B. (2001). A guide to carotenoid analysis in foods. Washington: International Life Sciences Institute.

Rózek, A., Achaerandio, I., Güell, C., López, F., \& Ferrando, M. (2010). Use of commercial grape phenolic extracts to supplement solid foodstuff. Lebensmittel-Wissenschaft + Technologie, 43(4), 623-631. http://dx.doi.org/10.1016/j.lwt.2009.11.002.

Rufino, M. S. M., Alves, R. E., Brito, E. S., Pérez-Jiménez, J., SauraCalixto, F., \& Mancini-Filho, J. (2010). Bioactive compounds and antioxidant capacities of 18 nontraditional tropical fruits from Brazil. Food Chemistry, 121(4), 996-1002. http://dx.doi.org/10.1016/j. foodchem.2010.01.037. 
Siqueira, E. M. A., Rosa, F. R., Fustinoni, A. M., de Sant'Ana, L. P., \& Arruda, S. F. (2013). Brazilian savanna fruits contain higher bioactive compounds content and higher antioxidant activity relative to the conventional red delicious apple. PLoS One, 8(8), 72-82. http://dx.doi. org/10.1371/journal.pone.0072826. PMid:23991156.

Southon, S. (1998). Increased consumption of fruits and vegetables within the EU: potential health benefits. In Proceedings of the 3rd Karlsruhe Nutrition Symposium (pp. 158-159). Karlsruhe: Bundesforschungsanstalt für Ernährung.

Souza, C. O., Silva, L. T., Silva, J. R., López, J. A., Veiga-Santos, P., \& Druzian, J. I. (2011). Mango and Acerola pulps as antioxidant additives in Cassava starch biobased film. Journal of Agricultural and Food Chemistry, 59(6), 2248-2254. http://dx.doi.org/10.1021/ jf1040405. PMid:21361289.

Souza, V. R., Pereira, P. A. P., Queiroz, F., Borges, S. V., \& Carneiro, J. D. S. (2012). Determination of bioactive compounds, antioxidant activity and chemical composition of Cerrado Brazilian fruits. Food Chemistry, 134(1), 381-386. http://dx.doi.org/10.1016/j.foodchem.2012.02.191.
Terada, M., Watanabe, Y., Kunitomo, M., \& Hayashi, E. (1978). Differential rapid analysis of ascorbic acid and ascorbic acid 2-sulfate by dinitrophenylhydrazine method. Analytical Biochemistry, 84(2), 604-608. http://dx.doi.org/10.1016/0003-2697(78)90083-0. PMid:626402.

Tonon, R. V., Brabet, C., \& Hubinger, M. D. (2010). Anthocyanin stability and antioxidant activity of spray-dried açaí (Euterpe oleracea Mart.) juice produced with different carrier agents. Food Research International, 43(3), 907-914. http://dx.doi.org/10.1016/j. foodres.2009.12.013.

Vasco, C., Ruales, J., \& Kamal-Eldin, A. (2008). Total phenolic compounds and antioxidant capacities of major fruits from Ecuador. Food Chemistry, 111(4), 816-823. http://dx.doi.org/10.1016/j.foodchem.2008.04.054.

Xu, B. J., Yuan, S. H., \& Chang, S. K. C. (2007). A comparative study on phenolic profiles and antioxidant activities of legumes as affected by extraction solvents. Journal of Food Science, 72(2), 167-177. http://dx.doi.org/10.1111/j.1750-3841.2006.00261.x. PMid:17995858. 